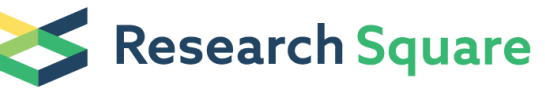 \\ Preprints are preliminary reports that have not undergone peer review. \\ They should not be considered conclusive, used to inform clinical practice, or referenced by the media as validated information.
}

\section{Knowledge, attitudes and practices (KAP) to assess the impact of school children's awareness of malaria using the MOSKI KIT® tool: study case of some Dakar schools in Senegal}

\section{Isaac Akhénaton Manga ( $\nabla$ akhenmanga@yahoo.fr )}

UCAD: Universite Cheikh Anta Diop https://orcid.org/0000-0002-5472-4296

\section{Aissatou Gaye}

UCAD FMPO: Universite Cheikh Anta Diop Faculte de Medecine de Pharmacie et d'Odontologie

Aliou Dia Kouevidjin

Medical Inspection Of Schools Of Dakar, Ministry Of Health And Social Action Of Senegal

Ekoue

UCAD FMPO: Universite Cheikh Anta Diop Faculte de Medecine de Pharmacie et d'Odontologie

Maria Rosa Dos Reis

UCAD FMPO: Universite Cheikh Anta Diop Faculte de Medecine de Pharmacie et d'Odontologie

Aboubakry Sadikh Niang

Pikine Guediawaye Academy Inspectorate, Ministry Of National Education , Senegal

Amy Ndao Fall

Sanofi Senegal

Christelle Maitre Anquetil

Sanofi France

Jean Louis Abdourahim Ndiaye

Parasitology Mycology, Departement Of Medical Biology, Ufr Santé Of University Of Thies

Research

Keywords: MOSKI KIT, Malaria, Knowledge, Attitudes, Practices, School children, Senegal.

Posted Date: November 19th, 2020

DOI: https://doi.org/10.21203/rs.3.rs-110521/v1

License: (c) (1) This work is licensed under a Creative Commons Attribution 4.0 International License.

Read Full License 
Version of Record: A version of this preprint was published at Malaria Journal on July 10th, 2021. See the published version at https://doi.org/10.1186/s12936-021-03829-5. 


\section{Abstract}

Background MOSKI KIT $\circledast$ is a fun tool designed to interest children for prevention and management of malaria. This study was carried out with the objective to assess the short- and long-term impacts of this tool on the knowledge, attitudes and practices of school children, and on the transmission of the knowledge received at the household level as well.

Method The study took place in elementary schools in the city center (with relatively low endemicity) and in the Niayes area (at high risk of anopheline and malaria) in the Dakar region of Senegal. The various schools chosen for our study were divided into an intervention group and a control group. The intervention schools were also divided into two subgroups, a full package subgroup and another partial package. We conducted three surveys there, a first before exposure to the MOSKI KIT ${ }^{\circledR}$, a second a week later and a third a year later. In the control schools, we only carried out one at the same time as the last in

the intervention schools. We carried out two household surveys (a week and a year after exposure) for the intervention schools, against one for the control schools.

Results Before sensitization, the proportion of school children with a grade above or equal to the average was $50 \%$ for the complete package subgroup (CPS) and $53 \%$ for the partial package subgroup (PPS). A week later, these proportions were $69 \%$ and $71 \%$ respectively for the complete and PPSs. A year later, they were $99.4 \%$ for the CPS, $98.1 \%$ for the PPS and $99.5 \%$ for the control group; The number of children who spoke to their parents about malaria was greater in intervention schools than that of control schools. They were $46.63 \%$ and $32.58 \%$ respectively in intervention and control schools.

Conclusion The MOSKI KIT, has enabled an increase of the knowledge of school children about malaria in the short term and favored its retention in the long term. However, its impact was not felt on their attitudes and practices.

\section{Background}

The number of malaria cases dropped by 20 million between 2010 and 2017, without forgetting that mortality also decreased by 172000 deaths in the same period (1). However, an analysis of the data for the period 2015-2017 highlights the absence of significant progress with regard to these indicators during this period (1). The emphasis must therefore be placed on prevention, especially in the context of the absence of an effective and certified vaccine. Raising awareness among children, who are both the most affected and the adults of tomorrow, would be one venue to explore; therefore, training them in prevention is essential. SANOFI initiated the "School Children Against Malaria" program in 2008 and developed the MOSKI KIT® tool in 2013 to support this initiative. The MOSKI-KIT $\circledast$ is a didactic and fun tool that addresses several themes on malaria, like: how do you get malaria? How do you prevent mosquito bites? How to fight against mosquitoes? How to recognize malaria and treat it? The MOSKI$\mathrm{KIT} \circledast$ is composed of the "MOSKI IMAGES ${ }^{\circledR}$ ", the "MOSKI CARD ${ }^{\circledR}$ ", the "MOSKI GAME®", a "teacher's book", and illustrated wall supports. 
This tool is currently being used in some West African schools heralding positive reports. Nonetheless its scaling up as a mean of raising awareness among local school-aged children is needed. With this in mind this study was carried out in collaboration with the National Malaria Control Program (NMCP), the Medical Division of Schools and a few Academic Inspection of the Ministry/Department Education in the Dakar region in Senegal. Our research question was to determine whether the use of games as teaching tools in schools could have an impact on the acquisition of knowledge and their retention. The objective was to assess the impact of raising awareness among school children on malaria using the MOSKI-KIT®, but also the relay role that school children could play within the community.

\section{Methodology}

\section{Study sites}

The study took place in elementary schools in the city center (with relatively low endemicity) and in the Niayes area (at high risk of anopheline and malaria) in Dakar region of Senegal. These schools belong to the academic inspectorates (Al) of Grand Dakar and Thiaroye in the suburb.

\section{Type and period of study}

The Knowledge, attitudes and practices (KAP) study was carried out in two phases over a period of 13 months between December 2018 and January 2019. We conducted a cohort study in the intervention group in which three KAP surveys were carried out before, one week and one year after awareness raising with the MOSKI-KIT®. We also compared this cohort to control group during the third test.

\section{Sampling and sample size calculation}

The Dakar region had been divided into two strata according to the endemicity of malaria: downtown Dakar (with relatively low endemicity) and the Niayes area (at high risk of anopheline). In the city center (Grand Dakar), the study took place in the Imam Abdou Ndiaye 1 and Imam Abdou Ndiaye. In the Niayes area (Thiaroye), these were Martyrs A; Martyrs B; Thiaroye Gare 1 B and Mame Moussé Niang schools. The different schools of our study were divided into an intervention group (used MOSKI KIT®) and a control group (never been in contact with MOSKI KIT®).

The main target consisted of pupils from Grades 4 (G4) and 5 (G5) classes of primary / elementary schools in Dakar during 2017-2018 school year. The required sample size (n) has been calculated according to the formula below:

$$
n=\frac{t^{2} p(1-p)}{d^{2}}=384
$$


Concerning the household survey, we enrolled all the parents of the pupils who gave a consent for their participation in the study

\section{Study participants}

The school children targeted for this study were those of the grades 4 (G4) and 5 (G5) in intervention schools the first year (2017-2018), and those of G5 and grade 6 (G6) for both types of schools the second year of our study.

A questionnaire validated by the director of each school was sent by the teachers to Parents who gave their consent participated to the household surveys

\section{Data Collection}

For the survey conducted before the sensitization and the one, a week later, the KAP data collection, was done on electronic tablets after downloading questionnaires from the Open Data Kit system (ODK). One year after, the survey was done on paper at the teachers request. The same questionnaire was used for each school children's survey. For household surveys, we administered the questionnaires through phone calls.

\section{Study description}

We divided the different selected schools into two groups: an intervention group (exposed to the MOSKI $\mathrm{KIT} \circledast$ ) and a control group (not exposed to the MOSKI KIT®). The intervention group was also divided into two subgroups: a complete package subgroup (CPS) (which used all the tools of the MOSKI KIT®) and a partial package subgroup (PPS) (which had used only the MOSKI IMAGES ${ }^{8}$ ). Within these schools we carried out different KAP surveys for school children (pre and post-tests)

\section{Data analysis}

The scale applied to the KAP surveys consists of assigning a score of 1 (one) to each correct answer and 0 (zero) to each wrong answer. The maximum score was 32 (22 in the KNOWLEDGE section, 3 in the ATTITUDES section and 7 in the PRACTICES section). Is considered as correct answer:

- an exact answer checked

- an incorrect answer not checked for multiple response questions

- the total note for a section constitutes the score of the rubric while the total sum of the marks is a overall score of the schoolchildren

The different data collected had been analyzed with the STATA statistical software. To appreciate the impact of awareness raising through the MOSKI KIT®, we took the proportion of school-children who had at least half of the maximum score. The Chi-square and Fischer tests were used according to their applicability condition for the comparison of proportions. 


\section{Ethical considerations}

Our study had obtained ethical approval from the National ethics committee for health research in Senegal under the number SEN16/71. Administrative authorization had also been requested from the Ministry of Health and the education authorities in the areas in which the selected schools were located. Parental consent for school children's participation and interviews was secured before the start of our study.

\section{Results}

\section{Cohort study}

In intervention schools, where we conducted a cohort study, 523 school children participated in the pretest survey with the MOSKI-KIT ${ }^{\circledR}$. During the second KAP survey (post-test), there were 516 and 327 a year later. In the control schools, we recruited 414 school children. The latter participated in the survey only a year later (Fig. 1).

Figure 1: Evolution of the number of school children between the different surveys

\section{Evolution of knowledge}

- Proportion of school children with a grade above or equal to the average in the knowledge section school children

Before sensitization, the proportion of school children with the average grade was $57 \%$ for the CPS and $65 \%$ for the PPS. However, this difference in proportion was not statistically significant $(p=0.07)$. One week after sensitization, they were $72 \%$ and $77 \%$ respectively for the CPS and PPSs. The use of the complete package had no more impact on the increase in knowledge than the use of the partial package of the MOSKI KIT® $(p=0.22)$. After one year, they were $99.4 \%$ for the CPS; $99.4 \%$ for the PPS and $100 \%$ for the control group. No statistically significant difference was noted between the different proportions of the groups one year after exposure. (Fig. 2).

- Difference in proportions of grades above or equal to the average in the two groups of school children in the knowledge section

The difference in the proportions of school children with a grade above or equal to the average, in the CPS, increased up to $15 \%$ and up to $42.4 \%$ respectively one week and one year after sensitization. In the PPS, it increased respectively up to $12 \%$ and up to $34.4 \%$ one week and one year after sensitization (Fig. 3).

\section{Evolution of Attitudes}

- Proportion of school children with grades above or equal to the average in the attitudes section 
Before sensitization, the proportion of school children with grades above or equal to the average was $51 \%$ for the CPS and $50 \%$ for the PPS $(p=0,90)$. After one week, these proportions were respectively $62 \%$ and $55 \%$ for the complete and partial package subgroups. We noted an increase in attitudes within the two groups one, week after exposure. Although this was more important for the CPS, it had no statistically significant difference $(p=0.84)$. After one year, they were $90 \%$ for the CPS, $90.4 \%$ for the PPS and $89.1 \%$ for the control group. No statistically significant difference was found between these groups by comparing them two by two. ( $p=1$ between CPS and PPS; $p=0,88$ between CPS and control group; $p=$ 0,76 between PPS and control group) (Fig. 4).

- Difference in the proportions of school children with grades above or equal to the average in the attitudes section

In the CPS, the difference in the proportion of school children with grades above or equal to the average increased up to $11 \%$ and up to $49 \%$ respectively one week and one year after the sensitization. In the PPS, it increased up to $5 \%$ and up to $40.4 \%$ respectively one week and one year later (Fig. 5).

\section{Evolution of practices}

\section{- Proportion of school children with grades above or equal to the average in the practices section}

Before sensitization, the proportion of school children with grades above or equal to the average was $37 \%$ for the CPS and $29 \%$ for the PPS without any statistically significant difference $(p=0.063)$. After one week, these proportions were $50 \%$ and $49 \%$ respectively for the complete and partial package subgroups. The increase in the proportion in the practical section was greater for the CPS compared to the PPS, but without any statistically significant difference $(p=0.92)$. After one year, they were $14.7 \%$ for the CPS, $26.1 \%$ for the PPS and $27.1 \%$ for the control group. The proportion of school children with good practices was higher in the PPS compared to the CPS and this difference was statistically significant $(p=0.015)$. When comparing the CPS to the control group, we also noted that practices were better in the control group. The difference in proportion was also statistically significant $(p=0.001)$. On the other hand, we did not note any statistically significant difference when comparing the proportions of the PPS and the control group $(p=0.244)$. (Fig. 6).

- Difference in the proportions of school children with grades above or equal to the average in the practices section

In the CPS, the difference in proportions increased up to $13 \%$ and up to minus $22.3 \%$ respectively one week and one year after sensitization. In the PPS, it increased up to more than $20 \%$ and up to less than $2.9 \%$ respectively one week and one year later (Fig. 7).

\section{Overall evolution of KAP}

Before sensitization, the proportion of school children with grades above or equal to the average was $50 \%$ for the CPS and $53 \%$ for the PPS, without any statistically significant difference $(p=0.55)$. A week later, these proportions were $69 \%$ and $71 \%$ respectively for the CPS and PPSs. No statistically significant 
difference was also noted between these two groups during the one-week post-exposure survey $(\mathrm{p}=$ 0.711). A year later, they were $99.4 \%$ for the CPS, $98.1 \%$ for the PPS and $99.5 \%$ for the control group (Fig. 8). Here too, no statistically significant difference was found with respect to both groups $(p=0.55$ between CPS and PPS; $p=1$ between CPS and the control group; and $p=0.43$ between PPS and control group).

\section{- Difference in the proportions of school children in the KAP}

In the CPS, the difference in proportions of school children with grades above or equal to the average increased up to $19 \%$ and up to plus $49.4 \%$ respectively one week and one year after MOSKI KIT ${ }^{\circledR}$ sensitization. In the PPS, it increased up to $18 \%$ and up to $45.1 \%$ respectively one week and one year later (Fig. 9).

\section{Household survey in the intervention group}

Of the 251 parents interviewed, $64 \%$ said that their children told them about malaria after the MOSKI KIT ${ }^{\circledR}$ sensitization. Among the latter $68 \%$ had their children in the PPS and $60 \%$ in the CPS. No statistically significant difference was found when comparing the groups $(p=0.188$ between CPS and PPS) (Fig. 10).

\section{The themes mentioned by school children}

Several subjects were tackled by school children at home. Fifty-two parents, including 16 for the CPS and 36 for the PPS, stated that their children spoke about how you get malaria. Seventy-three parents, including 29 for the CPS and 44 for the partial one, said that their children talked about how to fight mosquitoes. Twenty-two parents from the full package subgroup and 39 from the partial subgroup said their children talked about how to fight mosquito bites. finally, 12 parents of the complete package subgroup and 28 of the partial one, affirmed been aware of malaria symptoms treatment. (Fig. 11).

During the one-year household survey after exposure, 268 parents had agreed to participate in this one, $33.21 \%$ of whom (95\% Cl: $27.6 \%-39.2 \%$ ) had their children in control schools and $66.79 \%$ (Cl $95 \%: 60.8 \%$ $-72.4 \%$ ) in intervention schools. More children from the intervention schools spoke to their parents about malaria than those in control schools They were $46.63 \%$ and $32.58 \%$ respectively in intervention and control schools. Exposure to MOSKI-KIT ${ }^{\circledR}$ had an impact on knowledge transfer in families $(p=0.028)$. With regard to how does one catch malaria? $100 \%$ of parents in both schools said that their children had spoken to them about it. With regard to avoiding mosquito bites? $97.56 \%$ of parents from the intervention schools had heard about it from their children against $96.55 \%$ from the control schools. The exposure to the MOSKI-KIT ${ }^{\circledR}$ had no impact on the return of children in relation to this theme $(p=0.383)$. Among parents whose children were in intervention schools, $98.73 \%$ replied that their children had told them about how to control mosquitoes. This proportion was similar to that of parents in control schools (96.55\%). The exposure to the MOSKI-KIT® tool had no impact on the approach concerning this topic from children to parents $(p=0.466)$. How do you recognize malaria and treat yourself? The proportion of parents whose children had told them about it was higher in intervention schools (86.21\%) compared to 
that in control schools (67.86\%). This difference in proportions was related to exposure $(p=0.045)$ (Table 1).

Table 1

Proportions of school children whose parents answered "yes" to the different questions according to the school

\begin{tabular}{|llll|}
\hline Questions & $\begin{array}{l}\text { Intervention } \\
\text { schools }\end{array}$ & $\begin{array}{l}\text { Control } \\
\text { schools }\end{array}$ & p \\
\hline Did your child tell you about malaria? & $46,63 \%(83 / 178)$ & $\begin{array}{l}32,58 \% \\
(29 / 89)\end{array}$ & 0,028 \\
\hline Did he tell you how do you get malaria? & $100 \%(83 / 83)$ & $100 \%(29 / 29)$ & - \\
\hline Did he tell you how to avoid mosquito bites? & $97,56 \%(80 / 82)$ & $\begin{array}{l}96,55 \% \\
(28 / 29)\end{array}$ & 0,383 \\
\hline Did he tell you how to fight mosquitoes? & $98,73 \%(78 / 79)$ & $\begin{array}{l}96,55 \% \\
(28 / 29)\end{array}$ & 0,466 \\
\hline $\begin{array}{l}\text { Did he tell you how to recognize malaria and treat } \\
\text { yourself? }\end{array}$ & $86,21 \%(50 / 58)$ & $\begin{array}{l}67,86 \% \\
(19 / 28)\end{array}$ & 0,080 \\
\hline
\end{tabular}

\section{Discussion}

Our study aimed to assess the impact of games on learning and knowledge retention following the sensitization of school children on malaria with the MOSKI KIT®. Three KAP surveys were carried out a week before and a year after sensitization. An ascending curve in KAP was also witnessed the year following sensitization.

The limits of our study were constituted by the variation in the size of the cohort during the study and the lack of control over other sources of information on malaria. The variation in the number of school children, however, had no statistical impact because the minimum number of participants required was reached.

In our study, the school children already had a good knowledge of malaria before our intervention. This acquisition could likely be due to the protocol signed in 2002 between the Ministry of Health and Social Action and the Ministry of National Education (2). These two Ministries considered that it was important for teachers to have a guideline to provide relevant education on the fight against malaria. The guideline aimed at integrating basic knowledge about malaria and current means of prevention into the school curriculum (2). The "Zero Palu je m'engage" campaign, initiated and led by the Republic of Senegal since 2014 , which is based on the fundamental principle that everyone must play an active role in the fight against malaria and get involved to assume this role has also been a contributing factor (3). 
Progression in the intervention group was greater in both the short and long term. This increase was much more felt in the CPS. This shows the additional impact of the games. The use of educational and interactive games and cartoons as well are good ways to poke the interest of and to promote long-term information retention. (4). In India a study had shown that exposing school children to different health education activities such as live demonstrations, and slide shows when both events were grouped a high average of correct score (47.88\%) in comparison to that of control group (26.56\%) (5).

Comparing the intervention group to the control one, a year later, we noted no impact of the tool. The lack of difference between intervention and control schools in our study, could be explained by the radio and television programs on the fight against malaria broadcast at the request of the NMCP during the period of high transmission. It could also be explained by the lesson on malaria already taught before our survey.

During our study, raising awareness a week after had a positive impact on practices, regardless of the subgroup. But in the long term, we noted a decrease of these practices which were not as good in the control group. From this we inferred that whichever the group, the practices did not follow the main recommendations of the NMCP (1). This finding could be explained by the lack of use of prevention tools. In Senegal, a 2017 survey had shown that Dakar had the lowest rates of treated mosquito nets ownership and explained the use of these preventive materials is less envisaged in urban areas because the risk of malaria or the proliferation of mosquitoes is less perceived (6).

We noted a good appreciation of the MOSKI-KIT® by the teachers and the additional positive impact of games in the knowledge transmission. The positive role of games in long-term information retention among children had been already demonstrated in an analysis of the literature on the impact of play on learning (4).The role of relaying information by schoolchildren to their families noted during our study had also been found in studies in Kenya which had shown how action-oriented Child-Child learning methods enabled school children to help peers and parents gain health knowledge that favored changes their practices (7). Another study in the same country concluded that schools were an effective means of reaching a large section of the population, including future pregnant women and parents of young children (8). In fact, more than 2,500 students from the West and the East of the Democratic Republic of the Congo were made aware of the fight against malaria and then trained to become educators themselves because of strip cartoon entitled "How to fight against malaria" (9).

Children and especially those of school age, being the future their participation in the fight against diseases, in particular against malaria, is today an imperative. It becomes then, urgent to implement or disclose strategies intended for them, because of their susceptibility to malaria (10). These include IPT among school-aged children $(11,12)$ and educational tools such as the MOSKI KIT $\circledast$, the MOSKI BOOK® (the world of storytelling for prevention), MOSKI TOON ${ }^{\circledR}$ (a didactic cartoon), which should be added to the prevention and control strategies that already exist.

\section{Conclusion}


The good results obtained advocate for scaling up this tool among school children in rural areas. Using the MOSKI KIT ${ }^{\circledR}$ with an integrated approach could contribute to permanent behavioral changes from children, families and communities in general. The use of playful teaching materials in schools could be a good vehicle for raising awareness among schoolchildren and in general populations on diseases and public health problems.

\section{List Of Abbreviations}

Al: Academic inspectorates

CPS: Complete package subgroup

G4: Grade 4

G5: Grade 5

G6: Grade 6

KAP: Knowledge, attitudes and practices

NMCP: National Malaria Control Program

ODK: Open Data Kit

PPS: Partial package subgroup

\section{Declarations}

\section{Ethics approval and consent to participate:}

Our study had obtained ethical approval from the National ethics committee for health research in Senegal under the number SEN16/71. Administrative authorization had also been requested from the Ministry of Health and the education authorities in the areas in which the selected schools were located. Parental consent for school children's participation and interviews was secured before the start of our study

\section{Consent for publication:}

Our financial partner, SANOFI, had agreed to the publication of our research results. All participants in this study also knew that the results of the different surveys would also be the subject of a scientific publication.

\section{Availability of data and materials:}


Data from our study are available and archived at the parasitology-mycology department of the faculty of medicine of the Cheikh Anta Diop University of Dakar

\section{Competing interests}

The authors declare that they have no competing interests;

\section{Funding}

SANOFI

\section{Authors' contributions}

Study design: IAM, EK, ANF, CMA, JLAN

Data collection: IAM, AGS, EK,

Monitoring and evaluation: AD, ASN, ANF, CMA, JLAN

Statical analysis: IAM, AGS, MRDR, EK and JLAN

IAM, AGS, MRDR, ANF, CMA, JLAN wrote the first draft.

All authors reviewed and edited the last manuscript

\section{Acknowledgements}

To SANOFI

To all schoolchildren, teachers and school directors of our study sites.

Education and training inspections of our study sites.

To the National Malaria Control Program

To the Department of Parasitology and Mycology of the Faculty of Medicine, Pharmacy and Odontology of the Cheikh Anta Diop University of Dakar

\section{References}

1. World Health Organisation. World malaria Geneva, Switzeland; 2018.

2. Lutte contre le paludisme au Sénégal - Making malaria story. View 24/08/2019 www.makingmalariahistory.org >PARTENARIAT- SENEGAL-web.

3. African Union Malaria Progress Report 2018. Consulté le 12/07/2019. 
4. Sauvé L, Renaud L et Gauvin M. Une analyse des écrits sur les impacts du jeu sur l'apprentissage. Revue des sciences de l'éducation; 2007, 33(1).

5. Bhati PG1, Kant R, Srivastava HC, Malaviya VS, Pujara PK. Role of health education in schoolchildren with particular reference to malaria. Indian J Malariol. 1995 Sep;32(3):93-98.)

6. Programme National de Lutte contre le Paludisme. Enquête Nationale sur les Indicateurs du Paludisme au Sénégal, Rapport Final. Mai 2017

7. Onyango-Ouma W, Aagaard-Hansen J, Jensen BB. The potential of school children as health change agents in rural western Kenya. Soc Sci Med ; 2005 Oct, 61(8): 1711-1722.

8. Ogutu RO, Oloo AJ, Ekissa WS, Genga IO, Mulaya N, Githure JI. The effect of participatory school health programme on the control of malaria. (43) East Afr Med J;1992 Jun, 69(6): 298-302.

9. Slate Afrique. RDC : Une bande dessinée pour lutter contre le paludisme à l'école. Disponible sur : www.slateafrique.com > rdc-une-bande-dessinée-pour-lutter-contre-le-paludisme ; 25 avr. 2013.

10. Nankabirwa J, Cundill B, Clarke S, Kabatereine N, Rosenthal1 P, Dorsey G et al. Efficacy, Safety, and Tolerability of Three Regimens for Prevention of Malaria: A Randomized, Placebo Controlled Trial in Ugandan School children. PLoS ONE; 2010, 5(10), e13438.

11. Nankabirwa JI, Wandera B, Amuge P, Kiwanuka N, Dorsey G, Rosenthal PJ et al. Impact of Intermittent Preventive Treatment with Dihydroartemisinin-Piperaquine on Malaria in Ugandan School children: A Randomized, Placebo-Controlled Trial. Clin Infect Dis; 2014, 58(10): 1404-12.

12. Ndiaye JL, Cissé B, Ba EH, Gomis JF, Ndour CT, Molez F et al. Safety of Seasonal Malaria Chemoprevention (SMC) with Sulfadoxine-Pyrimethamine plus Amodiaquine when delivered to children under 10 years of age by district health Services in Senegal results from a stepped-Wedge cluster randomized trial. PLoS ONE ; 2016, 11(10), e0162563.

\section{Figures}




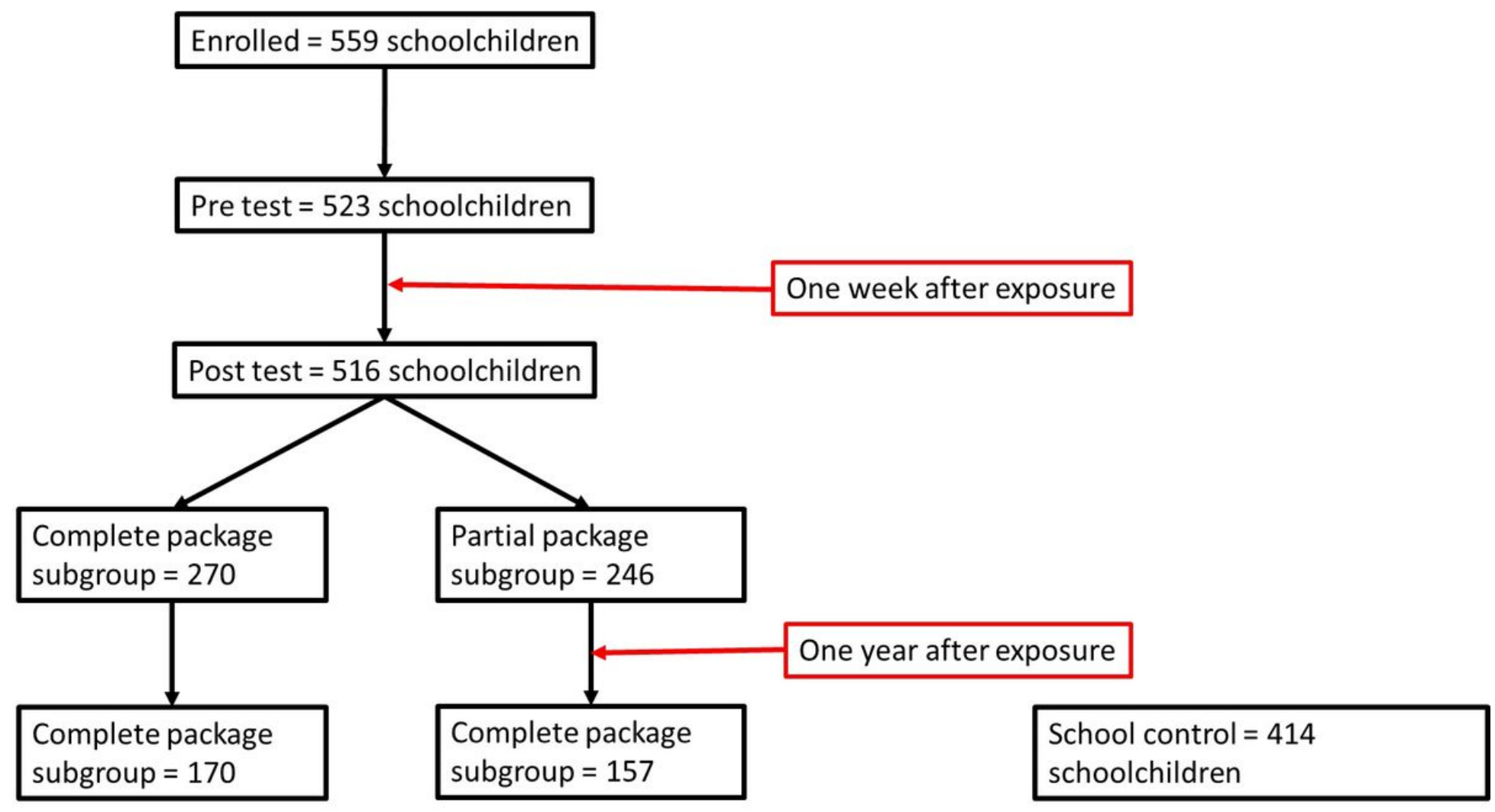

\section{Figure 1}

Evolution of the number of school children between the different surveys

complete

partial

control

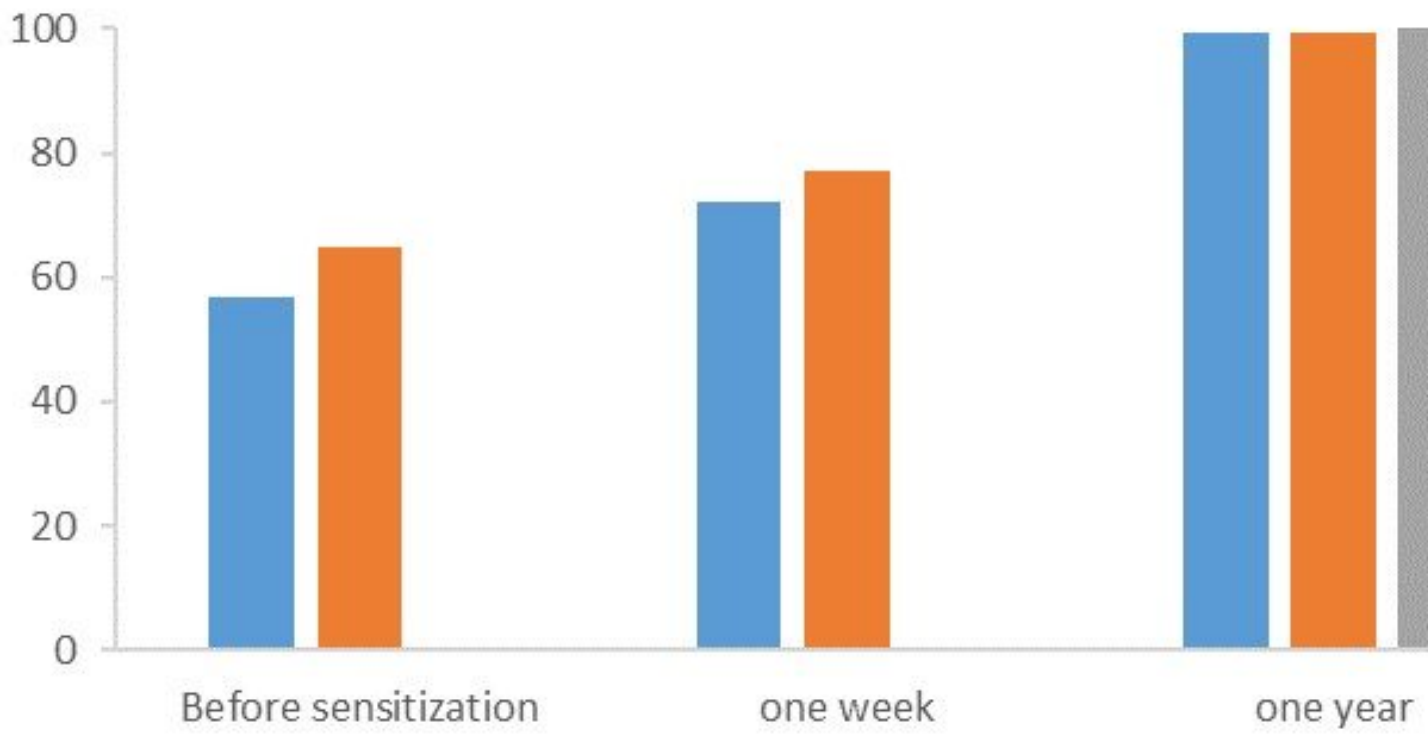

Figure 2 
Evolution of the proportion of school children with a grade above or equal to the average for knowledge

complete

partial

100

80

60

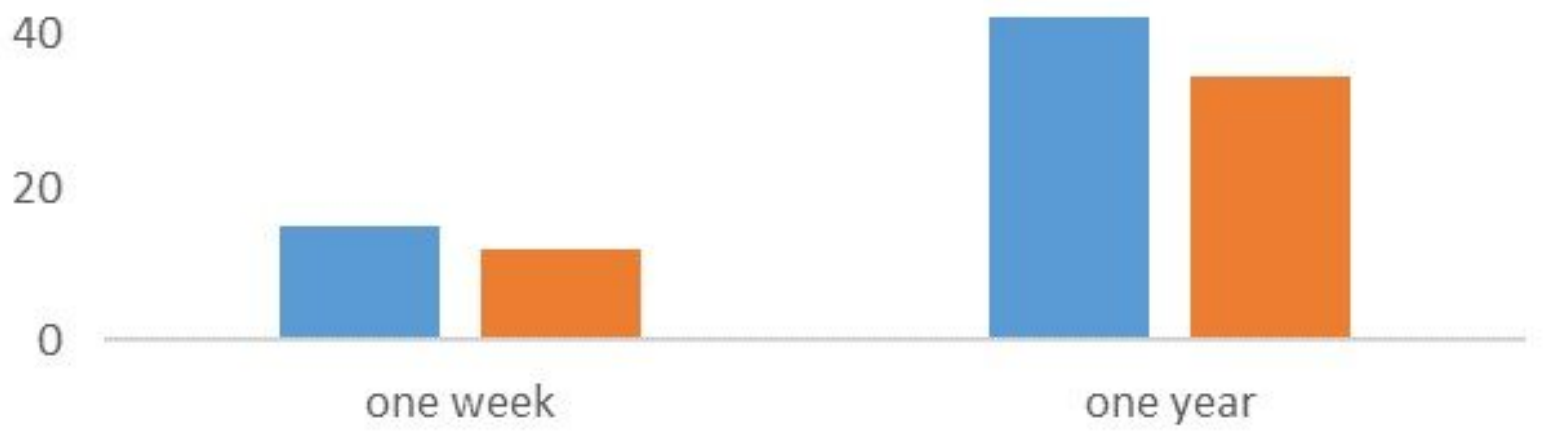

\section{Figure 3}

Difference in the proportion of grade above or equal to the average in the two groups for knowledge 
60

40
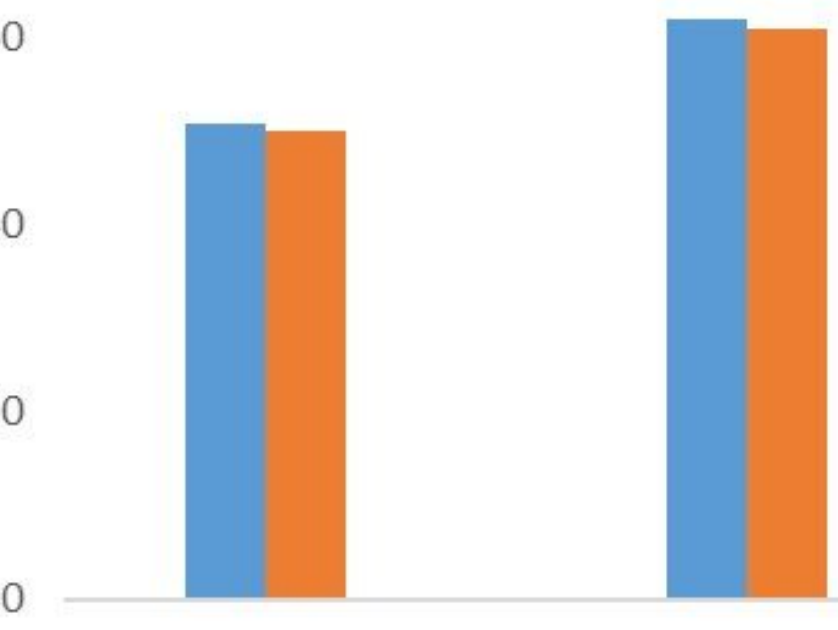

complete

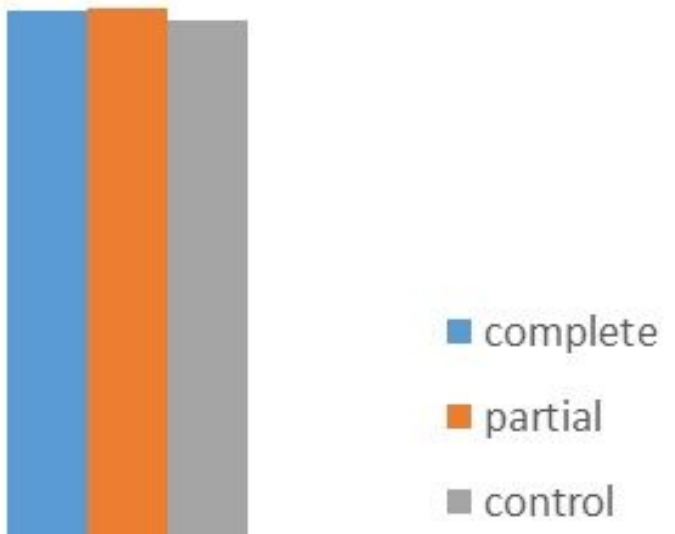

Before sensitization

one week

one year

\section{Figure 4}

Evolution of the proportion of school children with a grade above or equal to average for the attitudes 
complete

partial

100

80

60

40

20

0

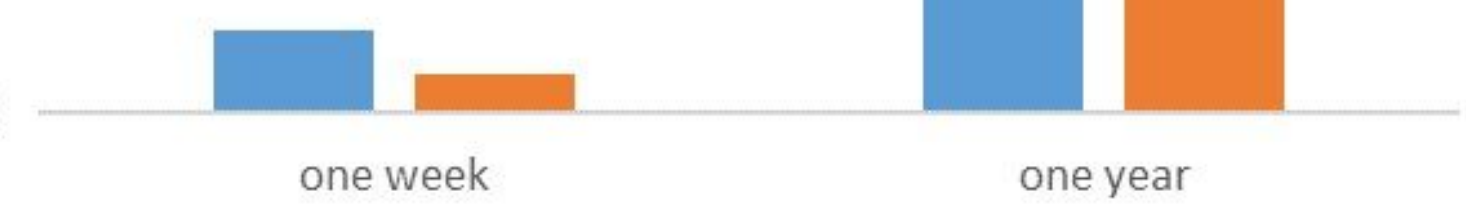

Figure 5

Difference in the proportion of school children with grades above or equal to the average for the attitudes

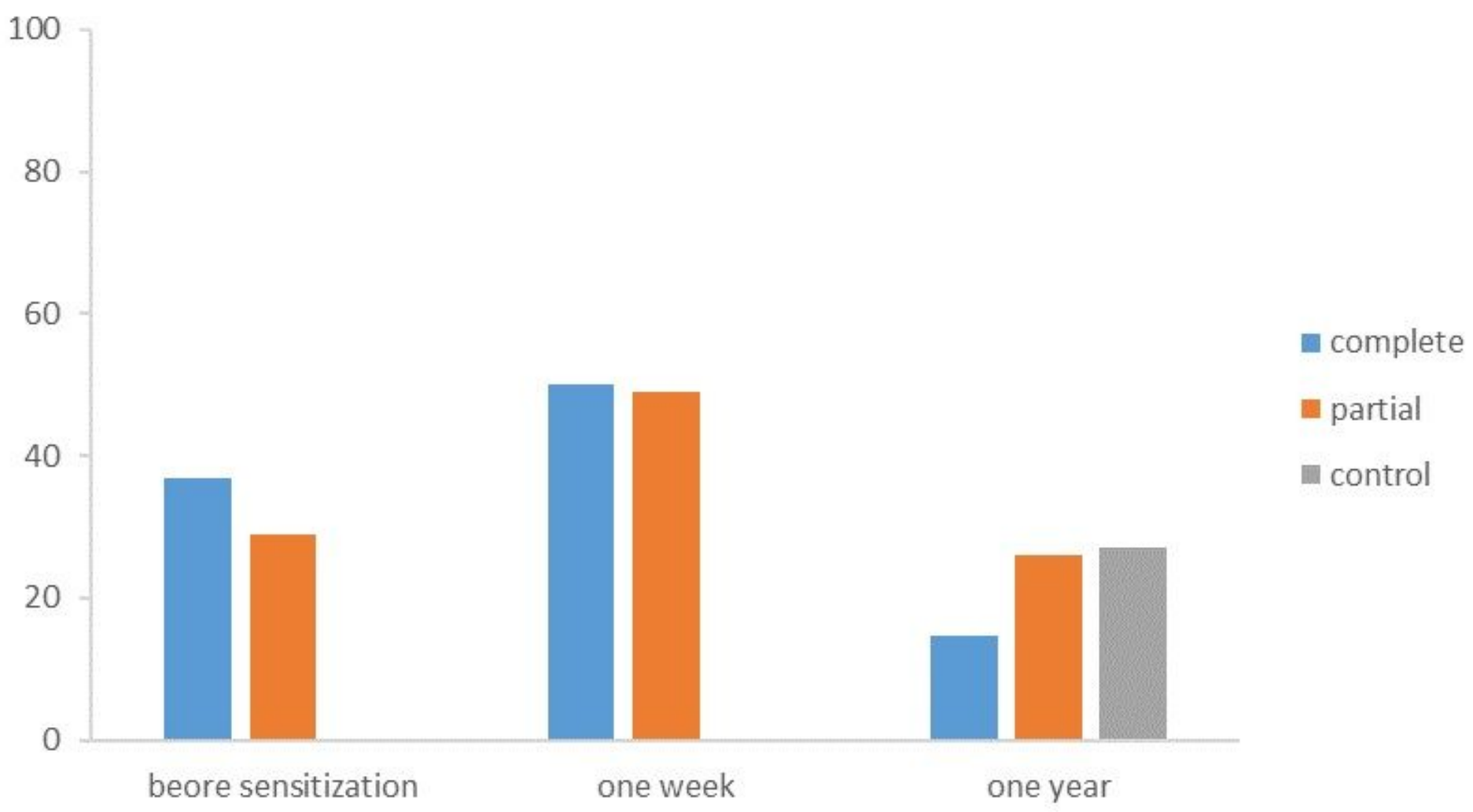


Figure 6

Evolution of the proportion of school children with grades above or equal to the average for the practices

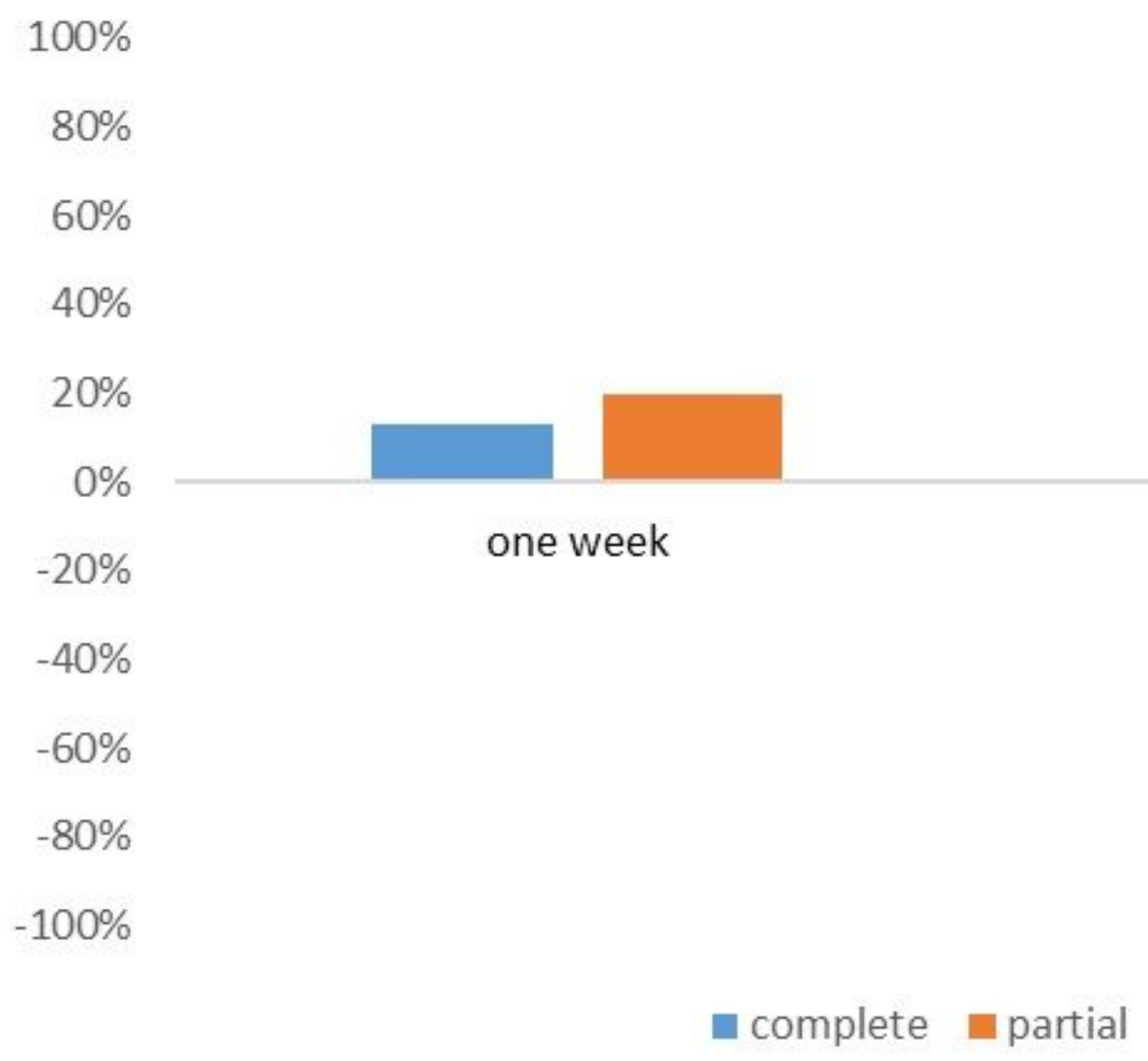

$-40 \%$

$-60 \%$

$-80 \%$

$-100 \%$

Figure 7

Difference in the proportion of practices with grades above or equal to the average 
coplete

- partial

몸 control

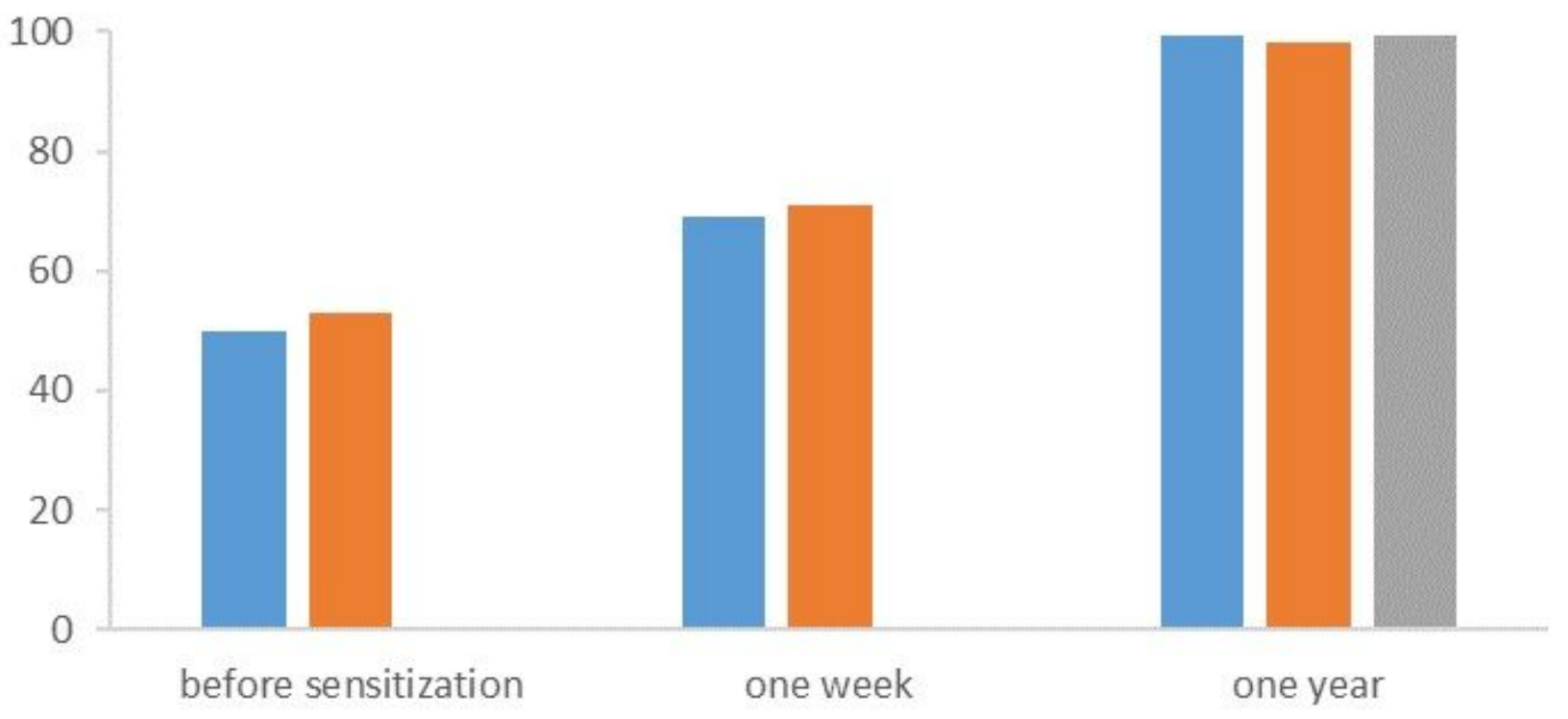

Figure 8

Evolution of the proportion of school children having overall grades above or equal to the average in the KAP 
80

60

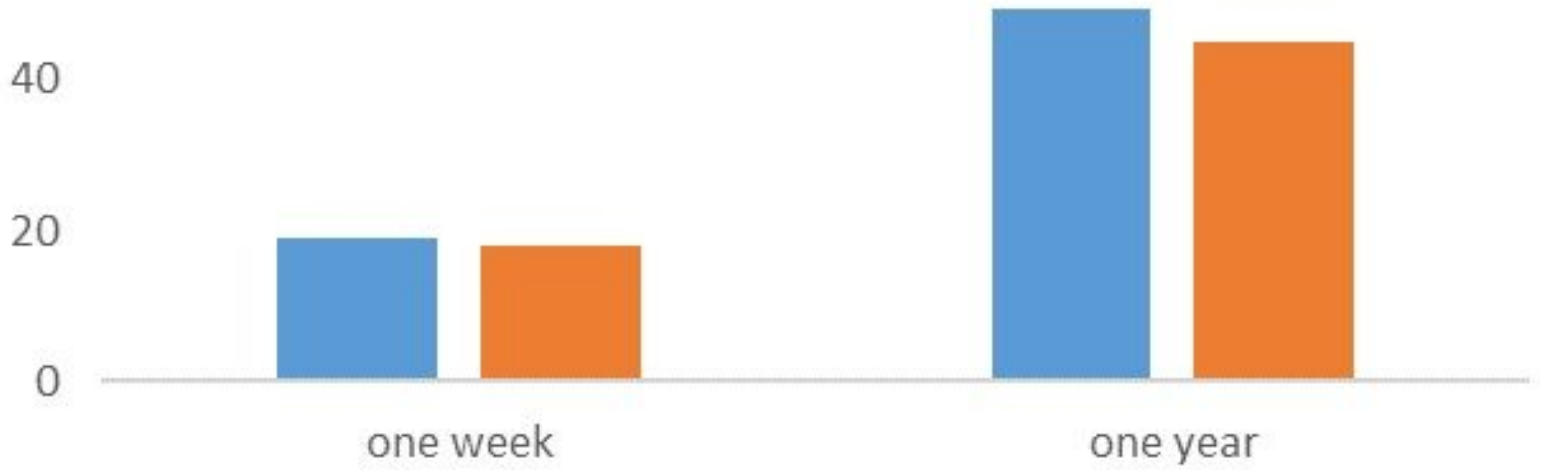

Figure 9

Difference in the proportion of KAPs with grades above or equal to the average 
80

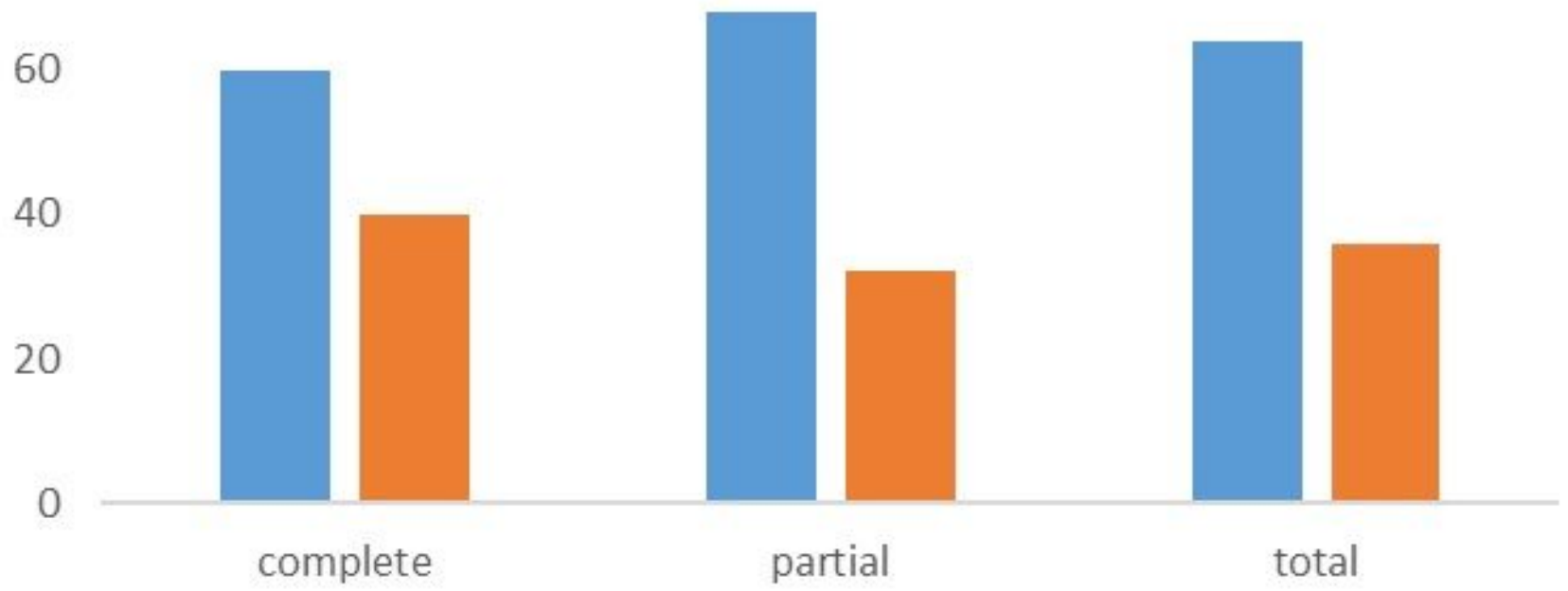

Figure 10

Distribution of parents interviewed according to the answer given and their children's sub-group 
80

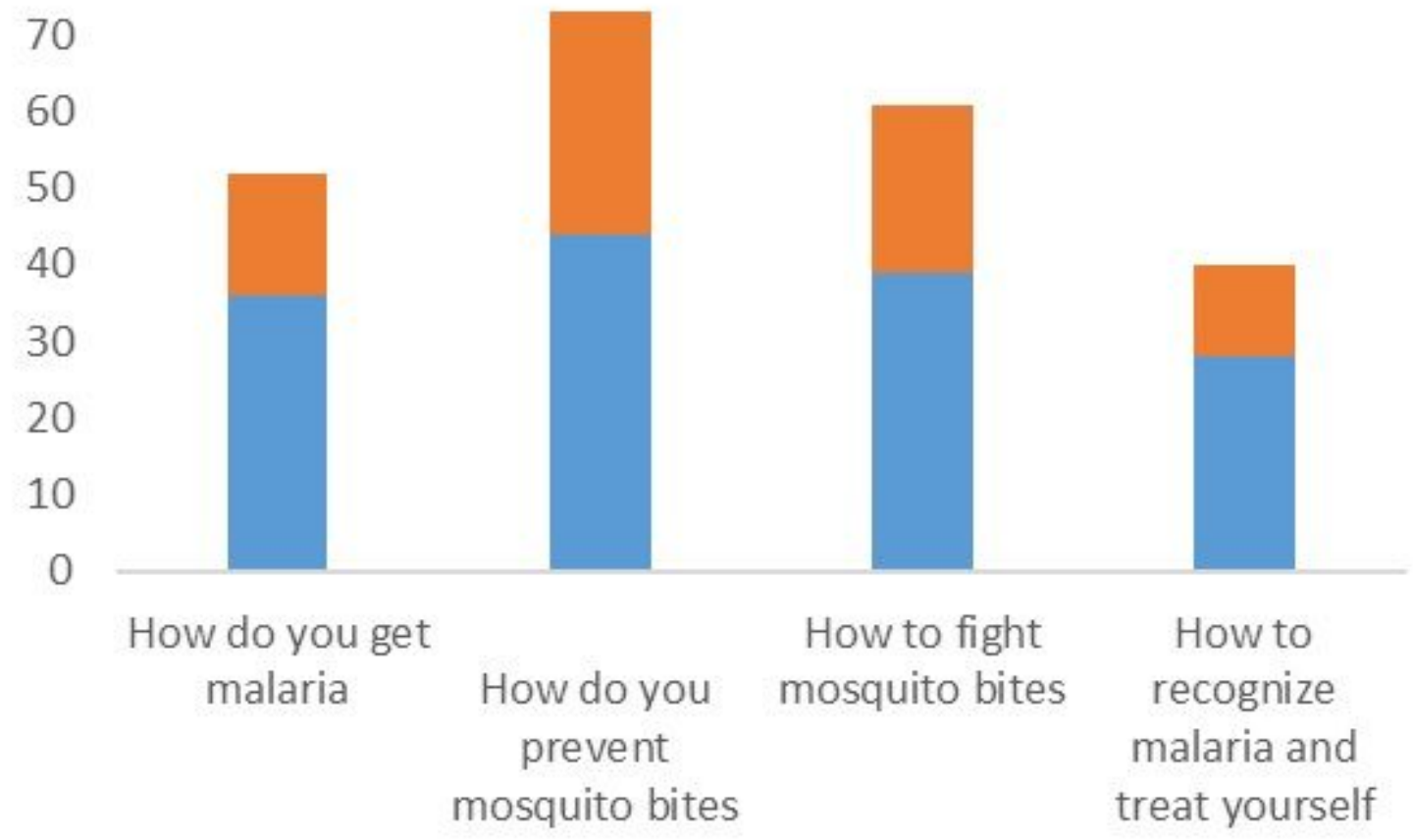

\section{Figure 11}

Number of parents according to the themes addressed by school children 